\title{
Holmium Laser enucleation of the prostate (HoLEP) versus Transurethral Resection of the Prostate (TURP)
}

\author{
Enucleação da próstata com Holmium Laser (HoLEP) versus Ressecção \\ Transuretral Da Próstata (RTUP)
}

Luís Eduardo Durães Barboza1', Osvaldo Malafaia, ECBC-PR², Luiz Edison Slongo³, Fernando Meyer¹, Paulo Afonso Nunes Nassif, TCBC-PR' ${ }^{1}$, Fernando Issamu Tabushi' ${ }^{1}$, Eduardo Wendler ${ }^{1}$, Rafael AleXandre Beraldi'

A $B$ S T R A C T

\begin{abstract}
Objective: to evaluate the effectiveness and applicability of Holmium laser enucleation of the prostate (HoLEP) - in the treatment of benign prostatic hyperplasia (BPH) - in comparison to transurethral resection of the prostate (TURP). Methods: patients with symptomatic prostatic hyperplasia and candidates for surgical treatment were selected. Both procedures were explained and they had choosen HoLEP or TURP. At the hospital were collected: age, date of birth, international prostate symptom score, urinary peak flow rate, prostate volume, post-voiding residual urine, globular volume and serum PSA. At the procedure operating time, morcellating time (HoLEP), bladder mucosal injury and intercurrences were collected. At the first postoperative day, globular volume and sodium. Besides that were observed the catheter indwelling time and hospital stay and after 90 days, urinary peak flow rate and international prostate symptom score. Statistical analisys have been done partially by Sinpe ${ }^{\circledR}$ and also by a professional team. Results: twenty patients in HoLEP group and 21 at TURP were operated. Baseline urinary peak flow rate was $8 \mathrm{ml} / \mathrm{s}$ in both groups and preoperative international prostate symptom score was 22 in HoLEP and 20 in TURP, very similar. Operative time was 85 minutes in HoLEP and 60 in TURP, $p<0.05$. Hospital stay was 47 hours for HoLEP and 48 hours to TURP, $p<0.05$. At 90 day the urinary peak flow rate was raised to $21.5 \mathrm{ml} / \mathrm{s}$ in HoLEP group and to $20 \mathrm{ml} / \mathrm{s}$ in TURP and the median of international prostate symptom score had been reduced to score 3 in both groups. Conclusion: HoLEP is a feasible technique and is as effective as TURP on symptomatic prostatic hyperplasia surgical treatment.
\end{abstract}

Key words: Prostate. Prostatic hyperplasia. Transurethral resection of the prostate. Laser therapy.

\section{INTRODUCTION}

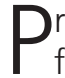
ostatic Benign Hyperplasia (BPH) is one of the most frequent diseases in men, and it has been considered part of the physiologic process of aging. The prevalence among 70 year-old men is around $40 \%{ }^{1}$. The gold standard surgical treatment is Transurethral Resection of the Prostate (TURP). New surgical techniques using lasers, as vaporization and Holmium Laser Enucleation of the Prostate (HoLEP) or Thulium laser (ThuLEP), have been known through many studies $^{2}$. Complications and morbidity related to TURP including blood loss, fluid balance disturbances, excessive fluid absorption, incontinence and erectile dysfunction, have been estimated to develop in about $15 \%$ of patients ${ }^{3}$.

In this scenario the laser treatment for BPH has challenged TURP due to advances in laser technology, better understanding of tissue-laser interactions and growing clinical experience ${ }^{4}$. Holmium Laser Enucleation of the Prostate, introduced by Gilling et al. ${ }^{5}$, seems to be an attractive alternative to standard TURP. The holmium: YAG laser (Lumenis®, Tel Aviv, Israel) is a pulse solid state laser with many characteristics that make it ideal for endourological surgery. It has a wavelength of $2.140 \mathrm{~nm}$ that allows it to be strongly absorbed by tissue water, therefore, causing rapid vaporization of exposed tissues at a depth of approximately $0.4 \mathrm{~mm}$ and producing coagulation 3 to $4 \mathrm{~mm}$ below the vaporization surface. This is useful and allows a precise, bloodless field, preventing systemic fluid absorption ${ }^{3}$.

In recent studies, HoLEP was as effective as TURP in terms of improving subjective symptoms and urodynamic findings with a 12 month followup ${ }^{3}$.

The purpose of this trial is to evaluate the effectiveness and applicability of Holmium Laser Enucleation of the Prostate (HoLEP) comparing it to TURP.

\section{METHODS}

The work was realized in the Programa de PósGraduação em Princípios da Cirurgia of the Faculdade Evan-

1. Faculdade Evangélica do Paraná, Curitiba - PR - Brazil; 2. Serviço de Urologia do Hospital de Clínicas da Universidade Federal do Paraná (HCUFPR) - PR - Brazil; 3. Pontifícia Universidade Católica do Paraná (PUC-PR) - PR - Brazil. 
gélica do Paraná, Hospital Universitário Evangélico de Curitiba, Instituto de Pesquisas Médicas e Hospital Nossa Senhora das Graças, Curitiba, PR, Brazil.

Patients with symptomatic prostatic hyperplasia and candidates for surgical treatment were selected. Both procedures were explained and they had chosen HoLEP or TURP.

The including criteria were: age above 45 and under 80 years old, maximum urinary peak flow rate under $15 \mathrm{ml} / \mathrm{s}$ and prostate sonography volume less than $100 \mathrm{~g}$. And the exclusion criteria were: neurogenic bladder, prostatic malignant disorder and previous surgery in the prostate, bladder neck or urethra.

We have created a protocol and these data were collected: age, date of birth, international prostate symptom score (IPSS), urinary peak flow rate, prostate volume, postvoiding residual urinary volume, globular volume and serum PSA. At the procedure: operating time, morcellating time (HoLEP), bladder mucosal injury and intercurrences (major and/or minor). At the first postoperative day, globular volume and sodium. After that catheter indwelling time and hospital stay. As major intercurrences/complications were considered: reoperation and blood transfusion; and as the minor ones: urinary retention and bladder mucosal injury during morcellation. After 90 days, new assessment of urinary peak flow rate and international prostate symptom score.

Patients have been operated on lithotomy position under regional anesthesia. Enucleation was performed at $2.0 \mathrm{~J}$ and $50 \mathrm{~Hz}, 100 \mathrm{~W}$ potency. The surgical technique was the previously described by Gilling ${ }^{5}$. The device was a continuous flow 26FR resectoscope sheath $(S t o r z \circledR)$ and a working element prepared for laser with a 550 micra fiber stabilized inside a 4FR ureteral catheter.

Following the enucleation, the tissue was morcellated with Versacut Morcelator (Lumenis $®$ ). All fragmented tissue has been sent to histological evaluation.

At the end of the procedure, a triple lumen catheter was inserted into the bladder and continuous irrigation was started.
The transurethral resection of the prostate was performed with monopolar eletrocautery $($ Wem $®)$ with a cutting current of $120 \mathrm{~W}$ and coagulating current of $80 \mathrm{~W}$.

For the data analysis was made up a platform with the software Sinpe ${ }^{6,7}$. We had chosen the Student t test. We also have performed statistical analysis by a Professional team to confirm the Sinpe outcomes inside each group and to evaluate between the groups. For HoLEP and TURP comparisons they had chosen the Student $t$ test or the Mann-Whitney and also the Kolmogorov- Smirnov, to verify normal condition of the data. P values under 0.05 indicate statistical significance. These data were analyzed with the software Statistica v.8.0.

\section{RESULTS}

Between June/2011 and May/2012, 20 patients in HoLEP group and 21 in TURP group were operated. The mean age was 68 (58-79) and 65 years (50-80) respectively. Prostate volume, total PSA, post-voiding residual urinary volume and pre-procedure urinary peak flow and IPSS are shown in table 1.

The difference in the post-voiding residual urinary volume was not statistically significant, neither the other data. Baseline urinary peak flow rate and IPSS were very similar, confirming the homogeneity between the groups. Operating time has considered all the time of the device in urethra, then including the morcellation in the Holmium technique. This mean time was 85 minutes in HoLEP and 60 in TURP, $p=0.02$. The mean morcellating time was 17 minutes. The mean hospital stay was 47 hours for HoLEP and 48 hours to TURP, $p<0.05$. The mean indwelling catheter time had no statistically significant difference, 48 hours for HoLEP and 45 hours for TURP. The baseline and postprocedure globular volume and also the post-procedure sodium were very similar in both groups. There were no major complications, i.e., blood transfusion or reoperation. As minor complications there were two patients in HoLEP group and one patient in TURP group who have had urinary

Table 1 - Patients characteristics.

\begin{tabular}{|c|c|c|}
\hline & HoLEP & RTUp \\
\hline Patients & 20 & 21 \\
\hline Mean age & $68 \quad(58-79)$ & $65 \quad(50-80)$ \\
\hline Prostate volume $\left(\mathrm{cm}^{3}\right)$ & 58 & 61 \\
\hline PSA (ng/ml)* & 1.5 & 3 \\
\hline Residual volume (ml) & 77.5 & 19 \\
\hline Baseline Qmáx (ml/s) & 8 & 8 \\
\hline Baseline IPSS** & 22.5 & 20 \\
\hline
\end{tabular}

*PSA: prostatic specific antigen

**IPSS: international prostate symptom score 
retention after catheter removal, and it was necessary to perform re-catheterization. Bladder mucosal injury, during morcellation, has occurred in 6 patients. Data shown in table 2.

One patient in HoLEP group was diagnosed with prostate cancer in the specimen analysis. He had been treated with radical prostatectomy.

On late assessment all patients were satisfied with both procedures and the mean IPSS was 3, for both groups. Urinary peak flow rate has risen to $21.5 \mathrm{ml} / \mathrm{s}$ in HoLEP group and to $20 \mathrm{ml} / \mathrm{s}$ in TURP group.

Comparing clinical outcomes before and after the procedures, there was remarkable improvement in both groups. Nineteen point IPSS reduction in HoLEP group and 17 in TURP. Also a peak urinary flow raising of $13.5 \mathrm{ml} / \mathrm{s}$ in HoLEP group and $12 \mathrm{ml} / \mathrm{s}$ in TURP. There was no statistically significant difference between the groups in these variables. Data shown in table 3.

On the other hand, when contrasting clinical outcomes before and after each intervention, we have seen a statistically significant difference (Figure 1 and 2).

\section{DISCUSSION}

Holmium laser enucleation of the prostate has become an attractive technique due to low morbidity and high efficacy; this is testified by symptom relief and also by objective assessment of urinary peak flow rate and complete urodynamic findings ${ }^{3}$.
In this study we have found a remarkable improvement on urinary symptoms in both groups, IPSS ranging from 22.5 to 3 points in HoLEP group and ranging from 20 to 3 in TURP group. Considering urinary peak flow rate we have seen the same improvement, $8 \mathrm{ml} / \mathrm{s}$ to $21.5 \mathrm{ml} /$ $\mathrm{s}$ in HoLEP group and from 8 to $20 \mathrm{ml} / \mathrm{s}$ on the other group. Data on literature confirms that functional outcomes are at least the same of TURP technique ${ }^{3,8}$.

Systematic review and meta-analysis have proved HoLEP to be the more testified technique with many reports confirming its safety and efficacy ${ }^{4,9}$. Ahyai et al. ${ }^{8}$ report that HoLEP outcomes can be even better than TURP on IPSS reduction and also on raising urinary peak flow rate. We report a similar efficacy because there was no statistical significant difference on late IPSS and urinary peak flow rate between the groups, as well as other reports ${ }^{3}$. Although the time of hospital stay favors HoLEP in our report and in other ones $3,8,10,11$ it was clinically irrelevant for the patient just one hour. Many advantages of HoLEP technique are due to hemostatic abilities of Holmium laser ${ }^{9}$. Catheter indwelling time is systematically lower when evaluating HoLEP versus TURP3,8,10,11. In this report this time was longer on HoLEP group than in TURP, although there was no statistically significant difference. Operating time was longer in HoLEP than in TURP, but with no statistically significant difference. Literature data confirms the longer operating time in the HoLEP technique ${ }^{3,8,10,11}$. It seems reasonable due to the extra time of morcellation. Although the longer operating time blood loss is not higher. Blood transfusion was not necessary on any patient.

Table 2 - Clinical data.

\begin{tabular}{lccc}
\hline & HoLEP & RTUp & value \\
\hline Operating time(min) & 85 & 60 & 0.020 \\
Morcellating time (min) & 17 & NA* & 0.002 \\
Hospital stay (h) & 47 & 48 & 0.527 \\
Catheter indwelling time (h) & 48 & 45 & 0.927 \\
Baseline GV** (\%) & 44 & 45 & 0.281 \\
Post-Procedure GV** (\%) & 41 & 42 & 0.306 \\
Post-Procedure Sodium & 140 & 140 & NA* \\
Bladder injury & $6(30 \%)$ & & \\
\hline
\end{tabular}

*NA: not assessable

**GV: globular volume

Table 3 - Comparing data between techniques.

\begin{tabular}{lrrr}
\hline & HoLEP & RTUp & P Value \\
\hline Baseline IPSS* & 22.5 & 20 & 0.603 \\
Baseline Qmáx(ml/s) & 8 & 8 & 0.533 \\
Post-procedure IPS5* & 3 & 3 & 0.533 \\
Post-procedure Qmáx(ml/s) & 21.5 & 20 & 0.329 \\
\hline
\end{tabular}

*IPSS: international prostate symptom score 


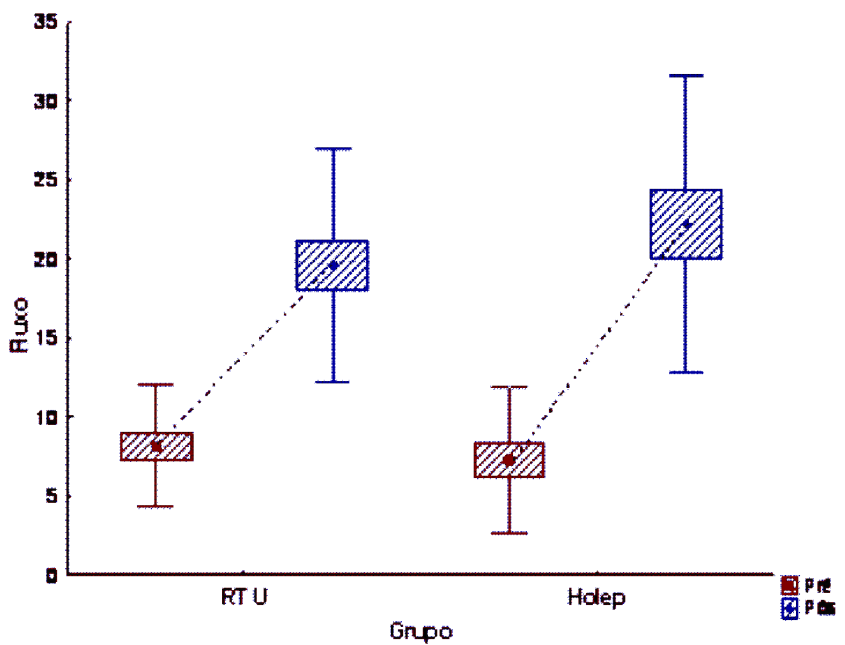

Figure 1 - Varying urinary peak flow on each group $(\mathrm{ml} / \mathrm{s})$, $p<0.001$.

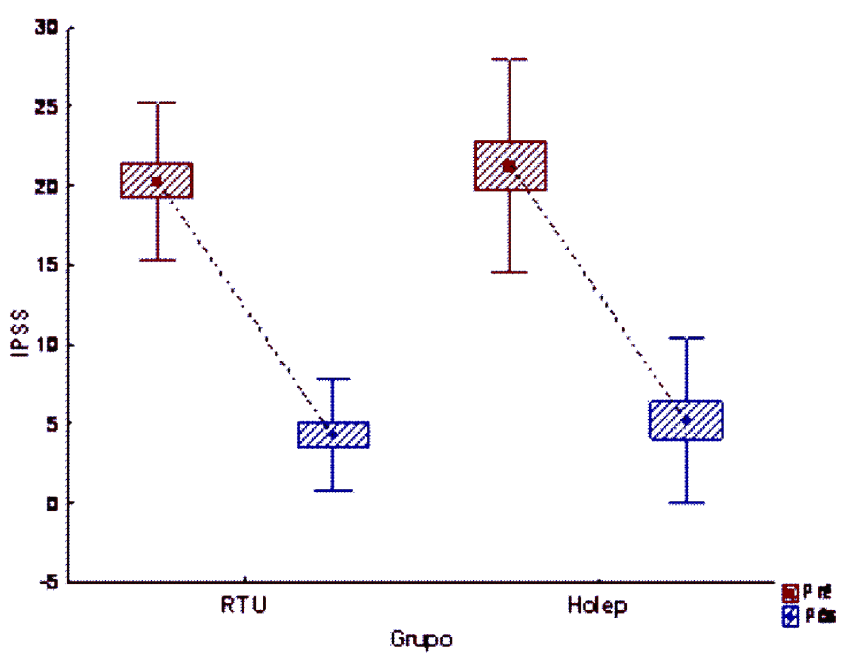

Figure 2 - Varying IPSS on each group, $p<0.001$.

Laser energy does not interfere on pathologist competence to prostate cancer detection. Placer et al. ${ }^{9}$ reports $4.8 \%$ of incidental cancer. One patient in HoLEP group $(5 \%)$ has been diagnosed with incidental adenocarcinoma. He had been treated with radical prostatectomy. This data ratifies that histological ability is preserved, as reported by other authors ${ }^{3,9}$.

When analyzing intraoperative complications we have found a high percentage of bladder injury, six patients in HoLEP group, i.e. $30 \%$. Placer et al. ${ }^{9}$ reports $4 \%$, Montorsi $^{3}, 18 \%$ and Elzayat and Elhiali ${ }^{10}$ less than $1 \%(1 /$ 118). The discrepancy between the values is marked and it happens because there is no uniformity on data classification. Some authors report all injuries and others report just that of clinical relevance. In the present analysis all injuries have occurred on morcellation, they were minimal mucosal lacerations that had not altered the surgery, nor catheter indwelling time and neither hospital stay.
Storage symptoms are frequent after HoLEP, $19.2 \%$. Nevertheless they do not last more than 1-2 months and the patients have improved with anticholinergic therapy ${ }^{9}$. Urgency after the HoLEP procedure is more frequent than in TURP, $5.6 \%$ vs $2.2 \%{ }^{8}$. It was not the objective of this study to evaluate storage symptoms.

On late complications, Montorsi reports that urethral stenosis was more frequent in TURP than in HoLEP ${ }^{3}$. Placer at al. ${ }^{9}$ reports that five patients (4\%) have developed bladder neck sclerosis. In our report there were no late complications, mainly by the short follow up period. One patient (5\%) in HoLEP group has developed bladder neck sclerosis at the sixth month; therefore this data is not in our outcomes.

Summarizing early and late adverse events are similar in both techniques 8,10 . There are in literature studies even comparing HoLEP with the open prostatectomy to $\mathrm{BPH}$ treatment. Kuntz at al. ${ }^{12}$ reported low per-operatory morbidity (15\% vs. $26.7 \%)$, and reduction in hemoglobin values (1.9 vs. $2.8 \mathrm{~g} / \mathrm{dl})$, catheter indwelling time (30 vs. $194 \mathrm{~h}$ ), and hospital stay (70 vs. $250 \mathrm{~h}$ ) were significantly lower in HoLEP technique. HoLEP and the open procedure evidence the same early and late re-intervention rate.

Reviewing all laser treatment options for $\mathrm{BPH}$, Gravas et al. ${ }^{4}$ have evidenced that HoLEP represents the endoscopic alternative to open procedure on $\mathrm{BPH}$ treatment and it is the most advanced laser prostatic surgery. Ahyai et al. ${ }^{8}$ report that prostatic cavity after enucleation is similar to that after the open procedure, and the enucleation technique has become candidate to replace TURP 8,10 .

HoLEP has a remarkable outcome on immediate $\mathrm{BPH}$ symptoms relief but also on late assessment. Elzayat and Elhilali ${ }^{10}$ has reported a five year follow up study demonstrating a $204 \%$ raise on urinary peak flow rate, $81 \%$ reduction in post-voiding residual volume and $67.6 \%$ IPSS reduction, with re-intervention rate of $4.2 \%$.

The main disadvantage of Holmium laser enucleation technique is the steep learning curve ${ }^{10,11}$, what keeps it in the large medical centers ${ }^{8}$. Placer et al. ${ }^{9}$ reports that this steep learning curve has limited its spread. Elzayat e Elhilali10 affirms that the curve is about 50 cases, but can be reduced to 27 under supervision of an experienced urologist.

HoLEP is internationally accepted, with evidence level 1, as an alternative for TURP and for open procedure ${ }^{11}$. Many clinical trials have proved its feasibility, efficacy, safety and cost-effectiveness ${ }^{9}$. Recent meta-analysis highlights HoLEP as a promising alternative ${ }^{13}$. In our study it was not different. We have got to perform all HoLEP procedures on adequate time. The patients are clinically well, both in symptomatic terms - assessed by IPSS - as in objective terms - assessed by urinary peak flow rate. These data were very similar to the TURP group, which is still the gold standard treatment for small and median volume prostates. Besides that, the technique has proved to be safe by the low blood loss and complication rate. 
Holmium laser enucleation of the prostate (HoLEP) is an effective technique on BPH treatment and can be performed in our country, because it has outcomes - in terms of effectiveness and applicability - equal to TURP.

\title{
R E S U M O
}

\begin{abstract}
Objetivo: avaliar a eficácia e a aplicabilidade da enucleação prostática com Holmium Laser (HoLEP), no tratamento da hiperplasia prostática benigna (HPB), comparando-a à ressecção transuretral da próstata (RTUp). Métodos: ambos os procedimentos eram explicados aos pacientes com indicação de tratamento cirúrgico e eles escolhiam qual procedimento seria realizado, HoLEP ou RTUp. Eram coletados dados da internação, dados clínicos, escore de sintomas e pico de fluxo urinário. No ato operatório registravam-se tempo cirúrgico, tempo de morcelamento (nos casos de HoLEP), lesão vesical ou intercorrências. Noventa dias após a operação era feita uma nova avaliação do pico de fluxo urinário e escore de sintomas. A análise estatística foi realizada em parte pelo programa Sinpe® e também por uma equipe profissional. Resultados: foram operados 20 pacientes no grupo HoLEP e 21 no RTUp. O pico de fluxo urinário pré-operatório foi $8 \mathrm{ml} / \mathrm{s}$ em ambos os grupos. O escore de sintomas pré-operatório foi 22 no grupo HoLEP e 20 no RTUp. O tempo operatório foi 85 minutos no grupo HoLEP e 60 minutos no RTUp, p<0,05. A internação hospitalar foi 47 horas para o grupo de HoLEP e 48 horas para RTUp, p<0,05. Na avaliação em 90 dias o fluxo urinário aumentou para 21,5ml/s no grupo HoLEP e para 20ml/s no RTUp e a mediana do escore de sintomas reduziu para 3 em ambos os grupos. Conclusão: o HoLEP é técnica tão eficaz quanto RTUp, no tratamento da HPB. A enucleação prostática com Holmium laser (HoLEP) é técnica eficaz no tratamento da HPB e pode ser aplicável, pois produz resultados, em termos de eficácia e aplicabilidade, comparáveis à RTUp.
\end{abstract}

\section{REFERENCES}

1. BahiaLR, AraújoDV, PepeC, Trindade M, Camargo CM, JavaroniV Cost-effectiveness analysis of medical treatment of benign prostatic hyperplasia in the Brazilian public health system. IntBraz J Urol. 2012;38(5):595-605.

2. JeongCW, Oh JK, ChoMC, Bae, JB, OhSJ. Enucleation ratio efficacy might be a better predictor to assess learning curve of holmium laser enucleation of the prostate. IntBraz J Urol.2012;38(3):36271; discussion 372

3. Montorsi F, Naspro R, Salonia A, Suardi N, Briganti A, Zanoni M, et al. Holmium laser enucleation versus transurethral ressection of the prostate: results of a 2-center, prospective, randomized trial in patients with obstructive prostatic hyperplasia. J Urol. 2004;172(5 Pt 1):1926-9.

4. Gravas S, BachmannA, Reich O, Roehrborn CG, GillingPJ,De La Rosette J. Critical review of lasers in benign prostatic hyperplasia (BPH). BJU Int. 2011;107(7):1030-43.

5. GillingPJ, KennettK, DasAK, ThompsonD, Fraundorfer MR. Holmium laser enucleation of the prostate (HoLEP) combined with transurethral tissue morcellation: an update on the early clinical experience. J Endourol. 1998;12(5):457-9.

6. Borsato EP. Modelo multicêntrico para elaboração, coleta e pesquisa de dados em protocolos eletrônicos [tese]. Curitiba: Universidade Federal do Paraná, Ciências da Saúde; 2005.

7. PintoJS. Interface de viabilização de informações para o Sistema Integrado de Protocolos Eletrônicos [tese]. 2005. Curitiba: Universidade Federal do Paraná, Ciências da Saúde; 2005.

8. Ahyai SA, Gilling P, Kaplan SA, Kuntz RM, Madersbacher S, Montorsi $F$, et al. Meta-analysis of functional outcomes and complications following transurethral procedures for lower urinary tract symptons resulting from benign prostatic enlargement. Eur Urol. 2010;58(3):384-97

9. Placer J, Gelabert-Mas A, Vallmanya F, Manresa JM, Menéndez $V$, Cortadellas $R$, et al. Holmium laser enucleation of prostate: outcome and complications of self-taught learning curve. Urology.2009;73(5):1042-8.

10. Elzayat EA, Elhilali MM. Holmium laser enucleation of the prostate (HoLEP): long-term results, reoperation rate, and possible impact of the learning curve. Eur Urol. 2007;52(5):1465-71.

11. Ahyai SA, Chun FK, Lehrich K, Dahlen R, Zacharias MS, Fisch MM, et al. Transurethral holmium laser enucleation versus transurethral resection of the prostate and simple open prostatectomy-which procedure is faster? J Urol. 2012;187(5):1608-13.

12. Kuntz R, Lehrich K, AhyaiSA. Holmium laser enucleation of the prostate versus open prostatectomy for prostates greater than 100 grams: 5-year follow-up results of a randomised clinical trial. Eur Urol. 2008;53(1):160-6.

13. Yin L, Teng J, Huang CJ, Zhang $X, X u$ D. Holmium laser enucleation of the prostate versus transurethral resection of the prostate: a systematic review and meta-analysis of randomized controlled trials. J Endourol. 2013;27(5):604-11.

Received on 02/09/2014

Accepted for publication 20/10/2014

Conflict of interest: none.

Source of funding: none.

Address for correspondence:

Luís Eduardo Durães Barboza

E-mail: luiseduardobarboza@hotmail.com 